BROOKHAVEN NATIOANL LABORATORY

Associated Universities, Inc.

Upton, New York

EP\&S DIVISION TECHNICAL NOTE

No. 62

C. T. Murphy

Apri1 30, 1973

\title{
MESB Design Notes: II. Mass S1it Operation and Pion Contamination
}

A mass slit for MESB is being built which is, basically, $40^{\prime \prime}$ of $\frac{1}{2}$ " heavimet backed by $36^{\prime \prime}$ of $1 \frac{1}{2} "$ brass. The heavimet pieces are split into $20^{\prime \prime}$ sections so as to permit sloping of the plates from the center of the mass slit; the slope should usually be $0.6 \mathrm{mrad}$. See page 4 (note by D. O'Brien) and Fig. 7 for mechanical details.

The above dimensions were arrived at by John Fox and myself, as the best compromise between the demands of various modes of the beam. The mass slit is designed to mask the highly aberrated pion image, with some loss of $\mathrm{K}^{\prime} \mathrm{s}$ in a manner described below. The worst conditions were assumed, namely, that the $B$ target is $4^{\prime \prime}$ long, that the beam is operating in that momentum range $(4-6 \mathrm{GeV} / \mathrm{c}$ $\mathrm{K}^{\prime} \mathrm{s}$, or $6-9 \overline{\mathrm{p}}^{\prime} \mathrm{s}$ ) in which the mode is chosen such that the separation of images is only twice the geometrical image width $(\eta=2)$, and the full momentum bite is being used. Experimenters running the beam at much lower momenta, or trying to push the beam to very high momenta, or whocan use a shorter production target, or who use a smaller momentum bite, may wish to reconsider the mass slit length and slope, and should perform the Monte Carlo studies described below under their particular conditions.

The remainder of this note describes the theory of the mass slit and applies it to modes 1,3 , and 4 of the beam. Lower limits are calculated for the number of pions which leak through. These numbers are lower limits because only the effects of chromatic aberrations and finite target length and breadth have been considered; magnet aberrations, separator non-uniformity and instability, and multiple scattering in windows, residual gas and collimator surfaces have not been considered.

Mass slit projections on vertical phase space at the mass slit.

It is easy to demonstrate that a mass slit whose dimensions in the vertical section, are:

$\pi$

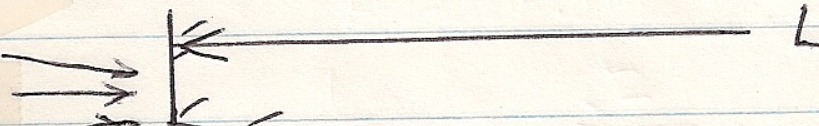
beam \&

intercepts all particles to the right of the open trapezoid superimposed on the phase space plot $\left(y, y^{\prime}\right)$ of the beam at the center of the mass slit, shown below: 
Column 6 gives the estimate of the pi/K ratio immediately following the slit, based on the pi/K ratios in front of the slit from Fig. 12, EP\&S 72-1 at the momentum shown in column 5 , the leak-through rate of column 4 , and the $\mathrm{K}$ attenuation of column 2. The last column gives the estimate of the $\mathrm{pi} / \mathrm{K}$ ratio at either MPS or the Carleton experiment in the East leg, by simply folding in a further decay loss. I reiterate that these are lower limits (see p. 1.)

Mass slit effectiveness; punch through estimate

The following are the properties of heavimet:

$\begin{array}{ll}\text { interaction length (omitting diffraction scattering): } & 4 " \\ \text { radiation length } & 0.2 " \\ \mathrm{dE} / \mathrm{dx} \text { minimum } & 50 \mathrm{MeV} / \text { inch }\end{array}$

Most pions traverse $40^{\prime \prime}$ of heavimet, or 10 interaction lengths, which leaves a negligible pion contamination. Those which pass through the mass slit at the edge of the trapezoid of Figs. 1-5 pass through considerably less material. Fig. 6 is a scatterplot of the length of material through which particles pass as a function of $\mathrm{y}$ and $\mathrm{y}^{\prime}$ for mode $3 \mathrm{E}$; the scale is the same as in Fig. 4. Multiplying the number of particles in each bin by the interaction probability leads to a punch-through rate of $0.6 \%$ for mode $3 \mathrm{E}$.

In most modes, the number of pions which punch through is somewhat smaller than the number which entirely miss the mass slit. Furthermore, pions which punch through, say, 4" of heavimet undergo multiple scattering of $13 \mathrm{mrad}$ ( $\mathrm{rms}$ ), which is much greater than the maximum vertical angle of the wanted particles $(2.3 \mathrm{mrad})$, so some of these particles will be stopped in the backup slit or in the pole pieces of D4. (These same particles lose a couple of hundred MeV/c in momentum in the mass slit, but this is not enough for them to be swept out of the beam by the downstream bending magnets.)

Mass slit: Mechanics (by D. O'Brien)

A schematic drawing of the mass slit is shown in Fig. 7. The blueprint of the mass slit is presently in the possession of the author. The flat top and bottom pieces of the mass slit are $1 \frac{1}{2} \times 36^{\prime \prime} \times 8^{\prime \prime}$ brass plates. There are four movable heavimet plates of dimensions $\frac{1}{2} " \times 20^{\prime \prime} \times 8^{\prime \prime}$ each. At the center $0.006^{\prime \prime}$ shims made of brass are available for varying the mass slit aperture. The upper half of the mass slit can be moved up or down relative to the lower half via screws mounted at the four corners of the structure. There is a screw at point A that permits the lowering and raising of (and also serves to hold up) the two upper heavimet plates for the insertion and removal of shims. The lower heavimet plates cannot be operated on in this manner and must be raised with screwdrivers via slots in the lower brass plate as seen in Fig. 7. The entire structure will sit on a table and, as a unit, it can be raised or lowered relative to the table by rotating its threaded legs. 
Table I- Predicted lower limits on the pion contaminations for 5 modes of MESB, based on the Monte Carlo plots of Figs. 1-5. The mometum bite 1isted in the last column is determined by the momentum collimator aperture, and is not a sharp bite, having tails whichextend another $\pm 1 \%$. Other constant conditions of the Monte Carlo runs are: target size $=0.040^{\prime \prime} \times 0.060^{\prime \prime} \times 4^{\prime \prime}$; production angle $=60$; horizontal acceptance at target $= \pm 20$ mrad; vertical acceptance so as to fill the $2^{\prime \prime}$ gap of the separators.

\begin{tabular}{|c|c|c|c|c|c|c|c|c|}
\hline Mode & $\begin{array}{c}\text { Уo } \\
\text { inches }\end{array}$ & $\begin{array}{l}\% \mathrm{k} \text { which } \\
\text { hit mass } \\
\text { slit }\end{array}$ & $\begin{array}{l}\% \text { pi } \\
\text { Miss }\end{array}$ & $\begin{array}{l}\text { which survive } \\
\text { Miss + punch- } \\
\text { through } \\
\end{array}$ & $\frac{\mathrm{P}}{\mathrm{GeV} / \mathrm{c}}$ & $\begin{array}{l}\mathrm{pi} / \mathrm{K} \\
\text { after } \\
\text { mass } \\
\end{array}$ & $\begin{array}{l}\mathrm{pi} / \mathrm{K} \\
\mathrm{at} \\
\exp ^{\prime} \mathrm{t} \\
\end{array}$ & $\Delta \underset{\%}{\mathrm{P} / \mathrm{P}}$ \\
\hline MPS 1 & .070 & 7.6 & 0.47 & 0.60 & 4.0 & 0.62 & 1.3 & 3.0 \\
\hline E 1 & .066 & 7.2 & 0.12 & 0.15 & 4.0 & 0.15 & 0.26 & 3.0 \\
\hline MPS 3 & .018 & 22.5 & 0.23 & 0.43 & 6.0 & 0.28 & 0.46 & 2.5 \\
\hline E 3 & .018 & 25.6 & 1.2 & 1.8 & 6.0 & 1.20 & 1.80 & 2.5 \\
\hline MPS 4 & .025 & 11.2 & 1.0 & 1.0 & 6.6 & 0.55 & 0.90 & 1.5 \\
\hline MPS 4 & $* .020$ & 21.0 & 0.14 & 0.24 & 6.6 & 0.14 & 0.23 & 1.5 \\
\hline
\end{tabular}

* Corresponds to dotted lines on Fig. 4: $\theta_{0}=0.3 \mathrm{mrad}, \mathrm{y}_{0}=1.0 \mathrm{x}$ image halfwidth.

Distribution - B1 Limited 


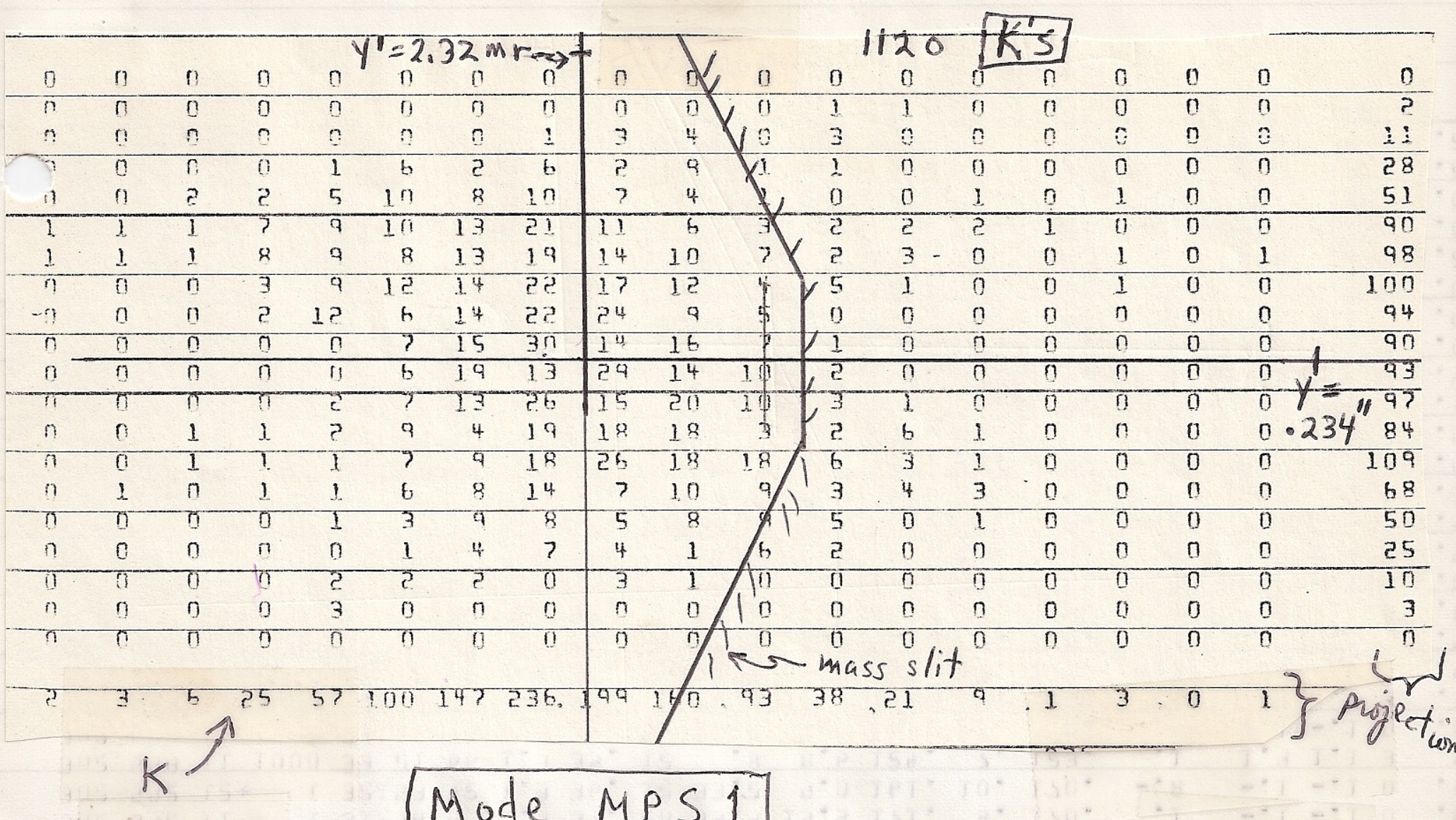

Mode MPS 1

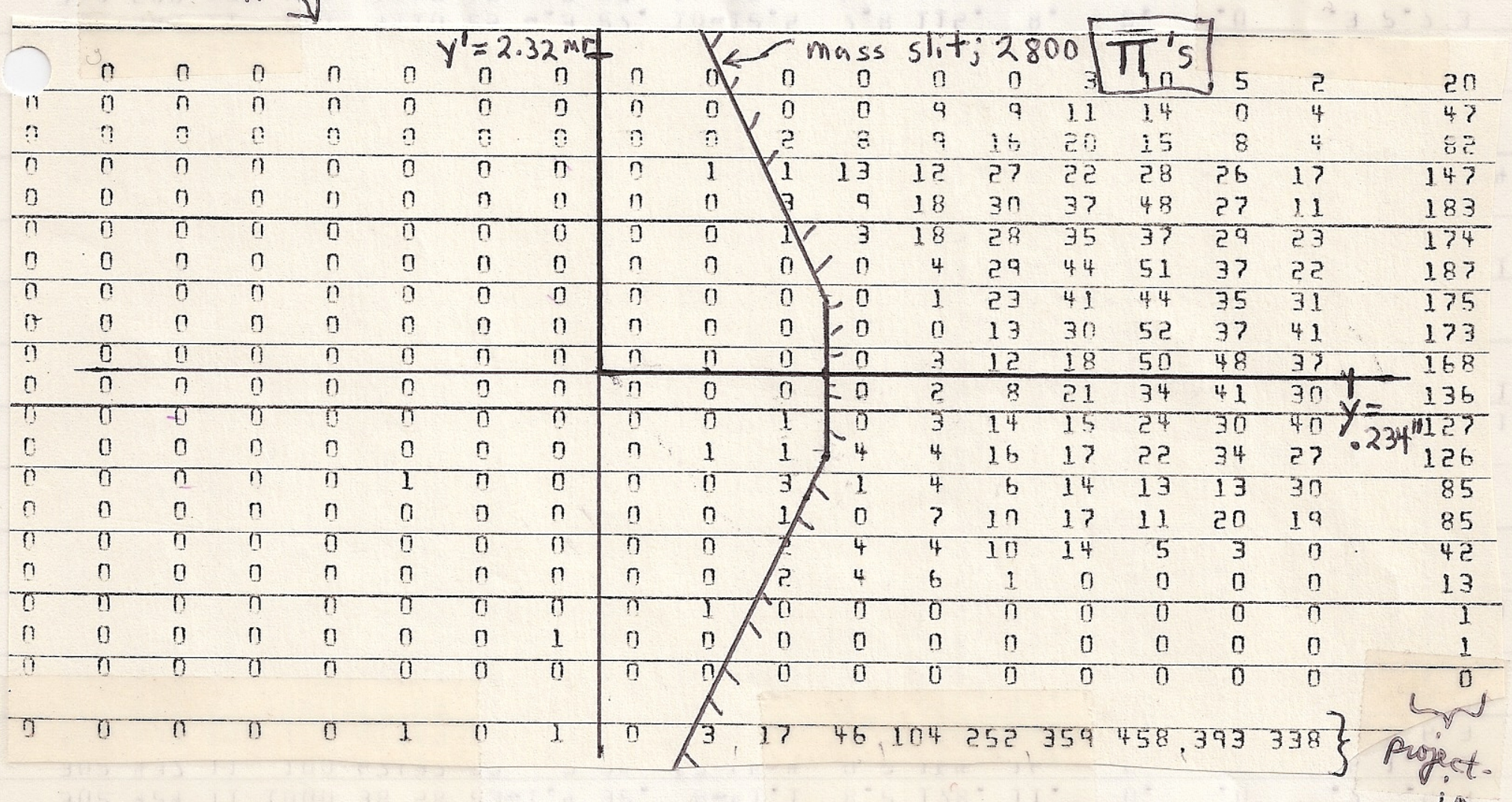

Fig. 1 - Phase space scatterplots of $K^{\prime}$ 's and $\pi^{\prime}$ 's at the mass sit for Mode MPS 1, from Monte Carlo nuns. The mass slit intercepts all particles to the right of the open trapezoid. 


\begin{tabular}{|c|c|c|c|c|c|c|c|c|c|c|c|c|c|c|c|c|c|c|c|}
\hline 3 & $?$ & 0 & 0 & $n$ & 0 & $y_{n}^{\prime}=$ & n & $n$ & $n$ & & & $\begin{array}{l}02 \\
1\end{array}$ & $\sqrt{0}$ & ${ }^{\prime} \rho S$ & 0 & 0 & 0 & 0 & $i$ \\
\hline 7 & 0 & 0 & 0 & 0 & 0 & 0 & 0 & B & 4 & 1. & 2 & 5 & $0^{\circ}$ & 0 & 0 & 0 & 0 & 0 & 12 \\
\hline ב & 0 & 0 & 0 & 0 & 0 & 4 & 3 & 6 & 5 & ? & 4 & 2 & 0 & 0 & 0 & 0 & 0 & 0 & 26 \\
\hline 0 & 0 & 0 & 1 & 0 & 4 & 2 & 7 & 11 & 9 & 8 & 5 & 3 & 1 & 0 & 0 & 0 & 1 & 0 & 50 \\
\hline 0 & 0 & 0 & 1 & 1 & 3 & 12 & 11 & 9 & 14 & 15 & & 2 & 2 & 1 & 0 & 0 & 0 & 0 & 77 \\
\hline 0 & 0 & 0 & 0 & 3 & 4 & $b$ & 4 & 10 & 13 & 10 & 6 & 5 & 3 & 1 & 0 & 0 & 0 & 0 & 65 \\
\hline 0 & 0 & 0 & 0 & 1 & $?$ & 11 & 9 & 3 & 13 & 1.8 & 3 & 3 & 4 & 0 & 0 & 0 & 0 & 0 & 72 \\
\hline 0 & 0 & 0 & 0 & 0 & 2 & 13 & 15 & 18 & 16 & 11 & 6 & 0 & 1 & 0 & 0 & 0 & 0 & 0 & 82 \\
\hline 0 & ก & 0 & 0 & 0 & 0 & ᄅ & 8 & 1.9 & 19 & 10 & ? & 1 & 0 & 0 & 0 & 0 & 0 & 0 & b. 1 \\
\hline n) & 0 & (1) & 0 & $n$ & 0 & 3 & 17 & 24 & 17 & 10 & $?$ & 0 & 0 & $n$ & ก & 0 & $\pi$ & $\pi$ & 28 \\
\hline 0 & 0 & 0 & 0 & 0 & 0 & ? & 18 & $1 ?$ & $1 ?$ & 13 & $h$ & 0 & 0 & 0 & 0 & 0 & 0 & 0 & 68 \\
\hline 0 & $\pi$ & 0 & 0 & 0 & 1 & 6 & I? & 23 & 16 & 16 & 5 & 0 & 0 & $\pi$ & 0 & 0 & 0 & 0 & 79 \\
\hline 0 & 0 & 0 & $n$ & 1 & 2 & 1 & 12 & 10 & 18 & 13 & 0 & 2 & 0 & 0 & 0 & 0 & 0 & 0 & $.226 \cdot 59$ \\
\hline n & 0 & 0 & 0 & 2 & 4 & 5 & 13 & 13 & 17 & 8 & 9 & 5 & 0 & 0 & 0 & 0 & 0 & 0 & 12679 \\
\hline 0 & 1 & 0 & ? & ? & 1 & $?$ & 12 & 9 & 12 & 10 & 2/ & 2 & 0 & 0 & 0 & 0 & 0 & 0 & 60 \\
\hline 0 & 0 & 0 & 2 & 2 & 9 & 6 & 12 & 10 & 10 & 8 & 8 & 2 & 3 & 0 & 0 & 0 & 0 & 0 & 70 \\
\hline 0 & 0 & 0 & 1 & 1 & 3 & 7 & $?$ & $?$ & $h$ & $?$ & 6 & 1 & 0 & 0 & 0 & 0 & 0 & 0 & 46 \\
\hline$\pi$ & 0 & 0 & 0 & 0 & 1 & 5 & 4 & 4 & $?$ & 8 & 0 & 0 & 0 & 0 & 0 & 0 & 0 & 0 & 29 \\
\hline 0 & 0 & 0 & 0 & 1 & 4 & 0 & 0 & 2 & 0 & 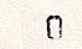 & 0 & 0 & 0 & 0 & 0 & 0 & 0 & 0 & $?$ \\
\hline 0 & 0 & 0 & 0 & 0 & 0 & 0 & $\pi$ & 0 & $n$ & & 0 & 0 & 0 & 0 & 0 & 0 & 0 & 0 & 0 \\
\hline 0 & 3 & 0 & $?$ & $1^{4}$ & 45 & $9 ?$ & 164 & 0 & 313 & & 35 & 32 & 14 & ट & 0 & 0 & 1 & 0 & \\
\hline
\end{tabular}

\section{Mode E1}

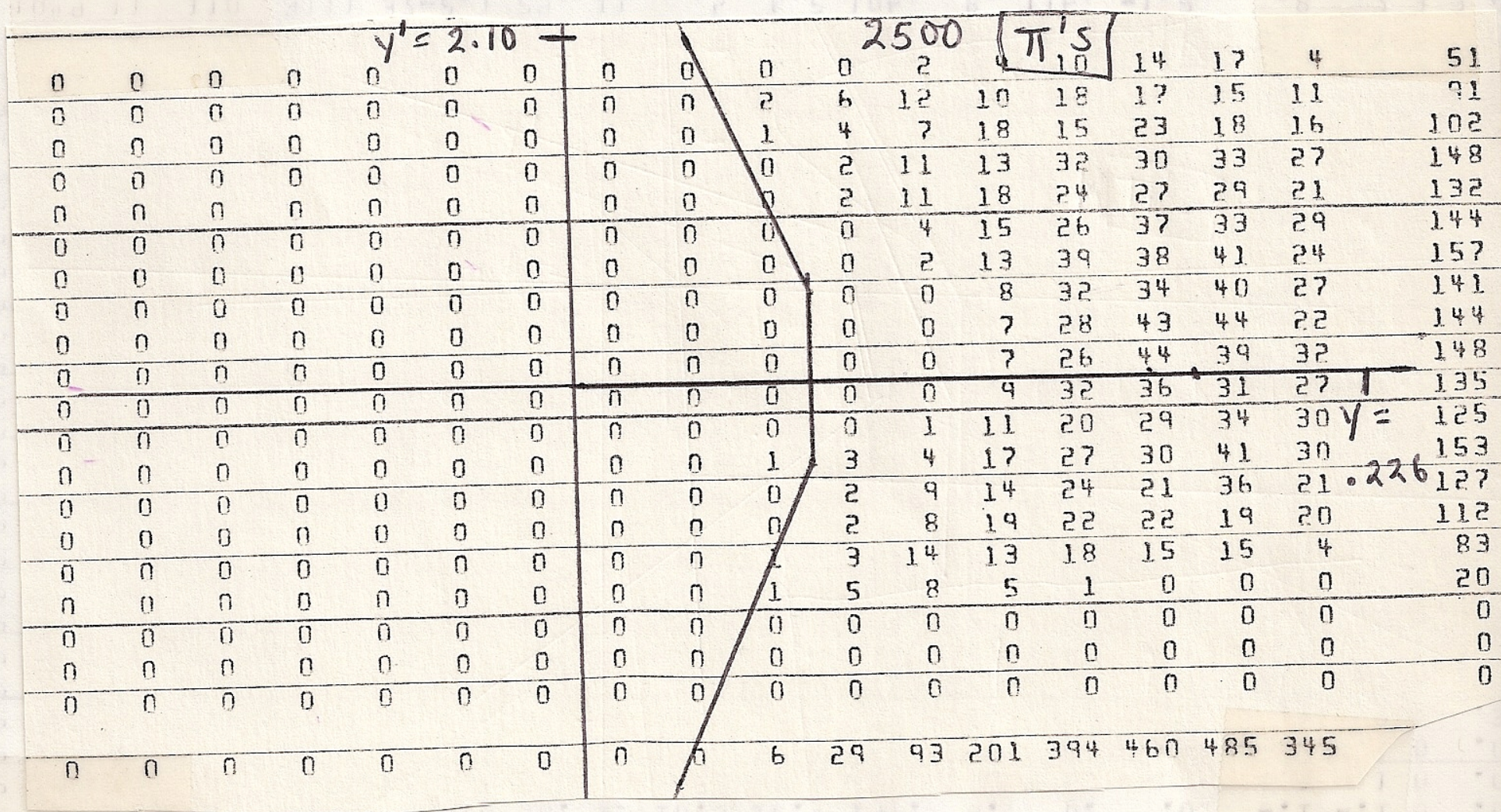

Fig. 2 - Mode EI
(see Fig.l caption) 


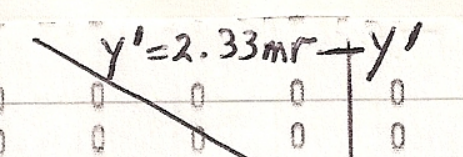

$[3450$ K's] $(780$ hit mass)

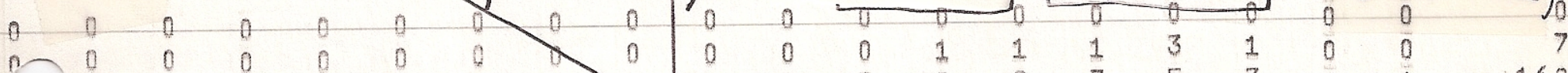

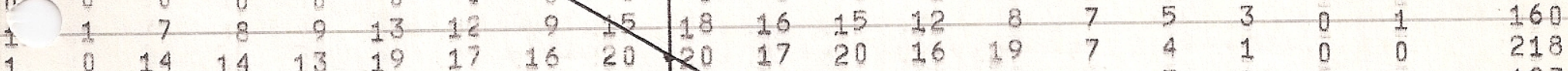

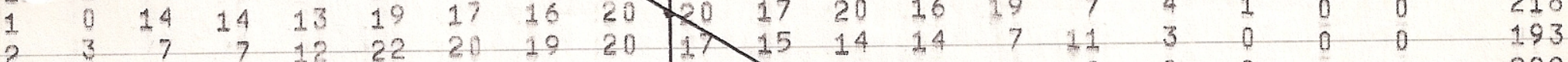

\begin{tabular}{lllllllll|llllllllll}
0 & 0 & 5 & 12 & 13 & 14 & 26 & 33 & 27 & 24 & 22 & 25 & 16 & 10 & 2 & 0 & 0 & 0 & 0
\end{tabular}

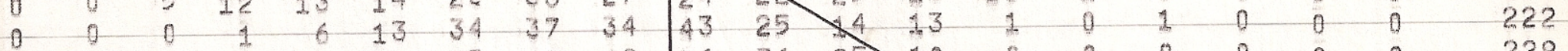

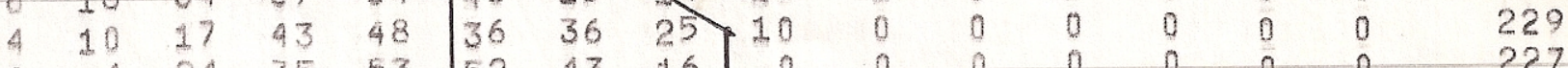

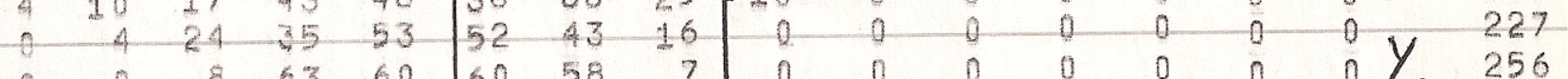

\begin{tabular}{lllll|lll|llllllll}
0 & 0 & 8 & 63 & 60 & 60 & 58 & 7 & 0 & 0 & 0 & 0 & 0 & 0 & 0 & 256 \\
0 & 0 & 2 & 50 & 44 & 56 & 49 & 7 & 0 & 0 & 0 & 0 & 0 & 0 & 0 \\
0 & 2 & 11 & 44 & 52 & 50 & 45 & 17 & 6 & 0 & 0 & 0 & 0 & 0 & 0 & 211 \\
0 & 7 & 31 & 227
\end{tabular}

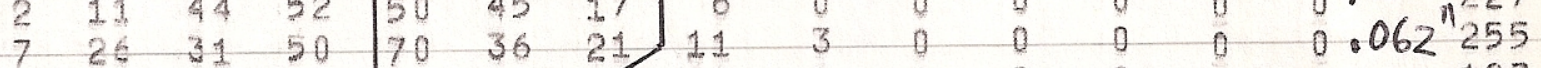

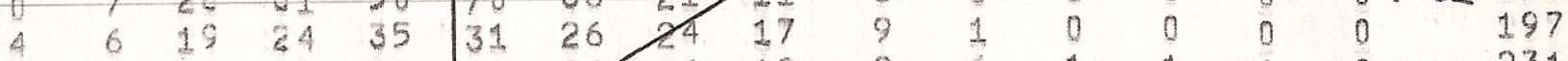

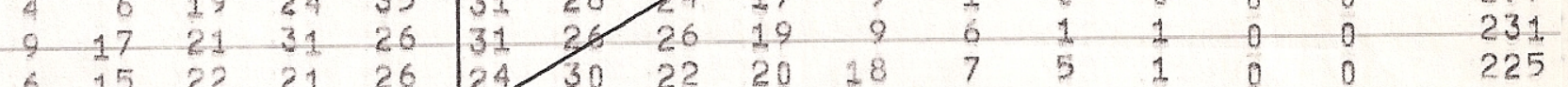

\begin{tabular}{lllll|llllllllll}
6 & 15 & 22 & 21 & 26 & 24 & 30 & 22 & 20 & 78 & 7 & 5 & 1 & 0 & 0
\end{tabular}

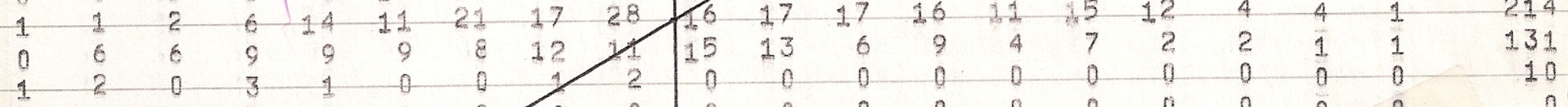

$\begin{array}{lllllllllllllllllll}0 & 0 & 0 & 0 & 0 & 0 & 0 & 0 & 0 & 0 & 0 & 0 & 0 & 0 & 0 & 0 & 0 & 0 & 0\end{array}$

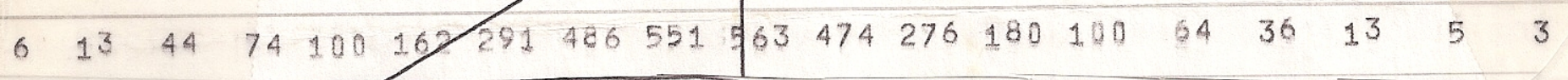

Mode MPS 3

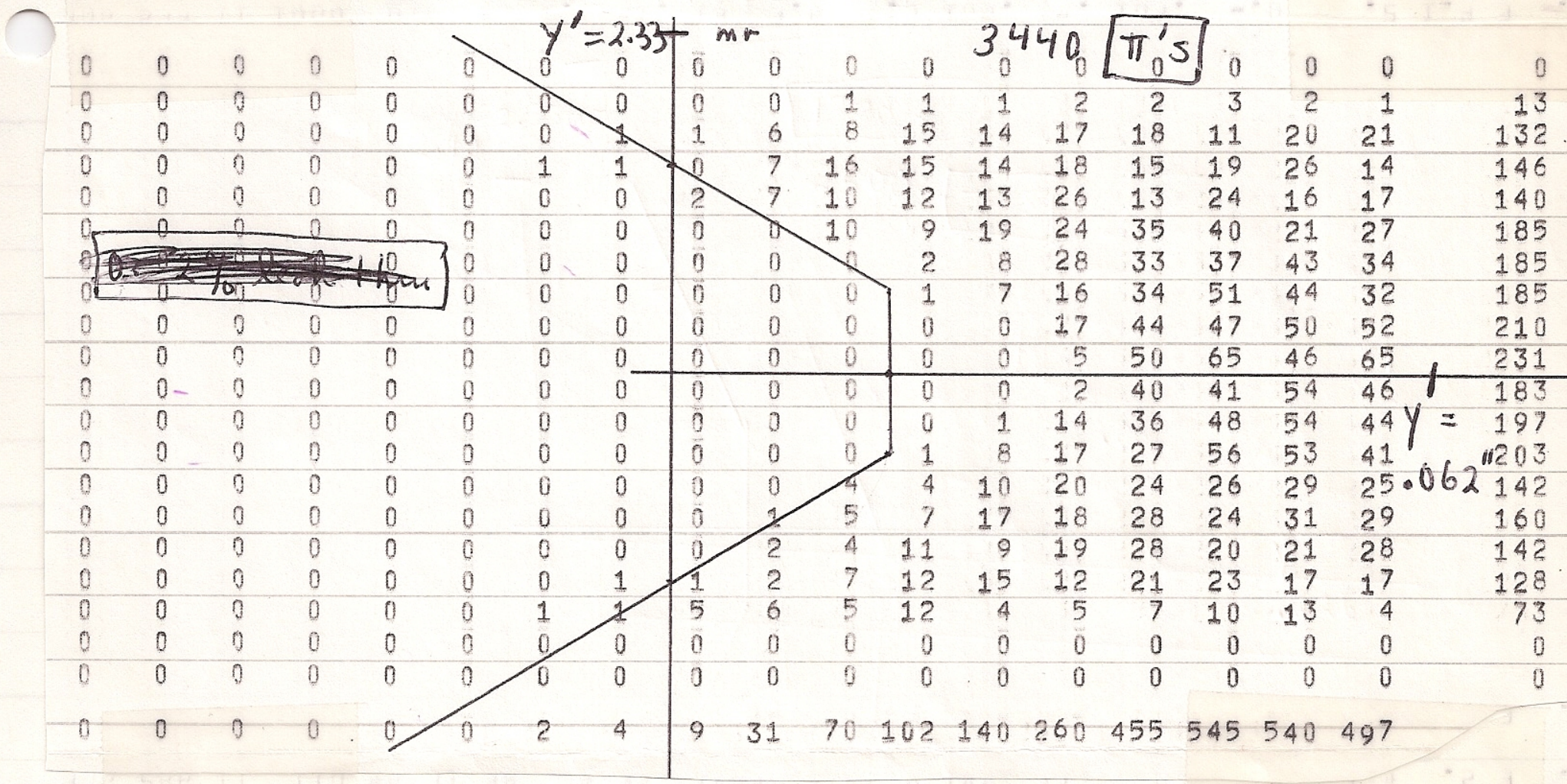

Fig. 3 - mode MPS 3

(see fig. I coption) 


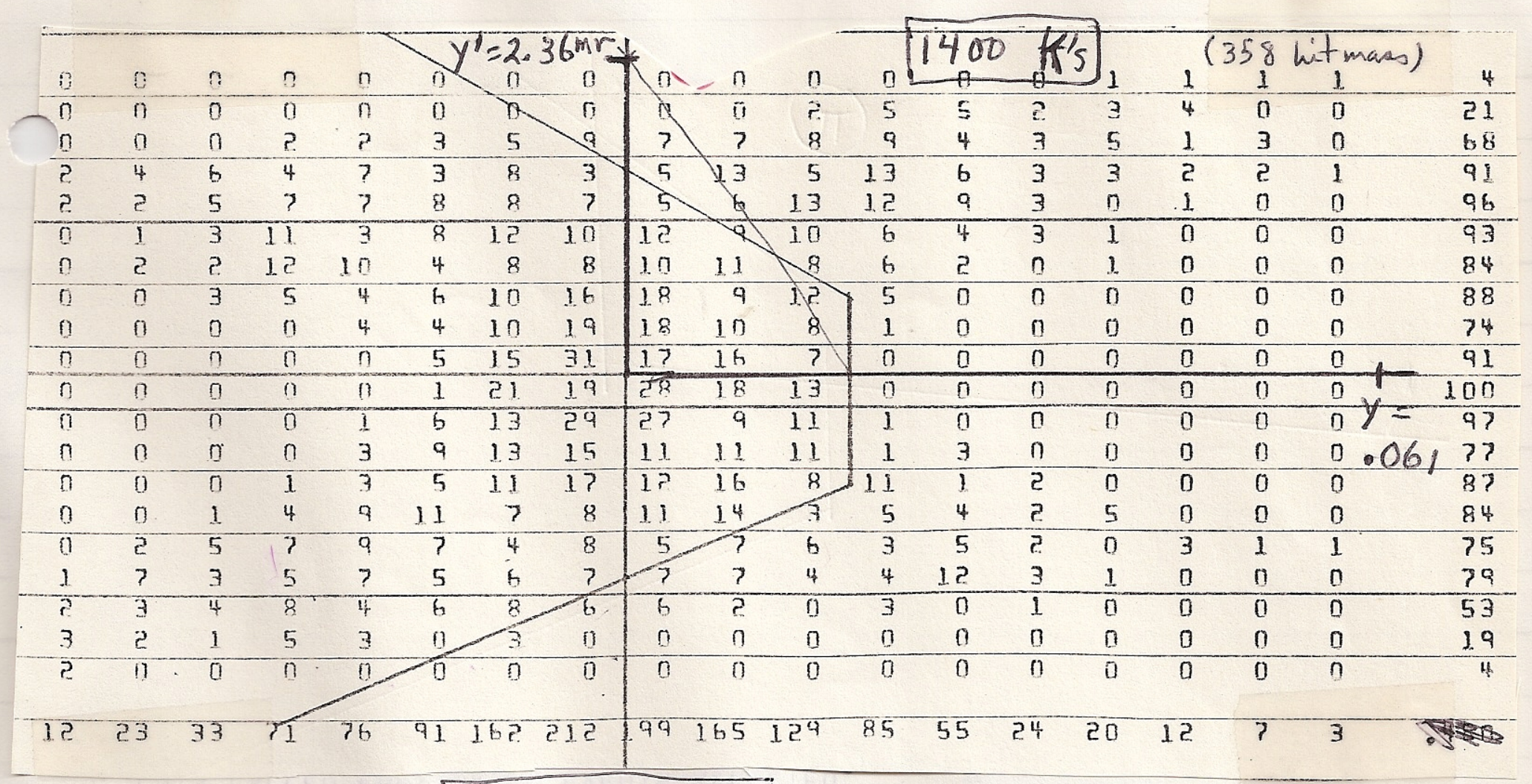

Mode E3

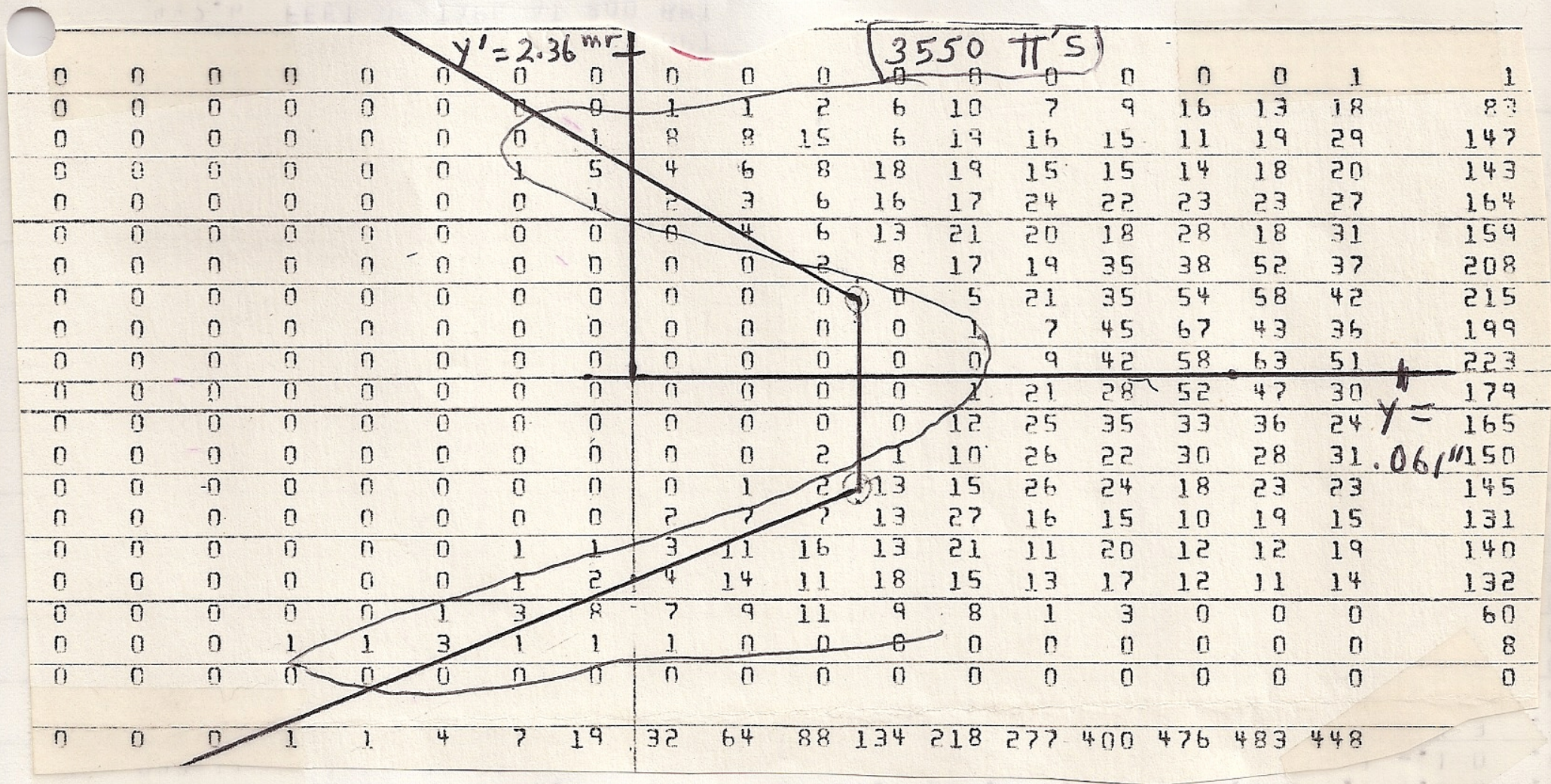

Fig.4 - Made E 3

(see Fig. I caption) 


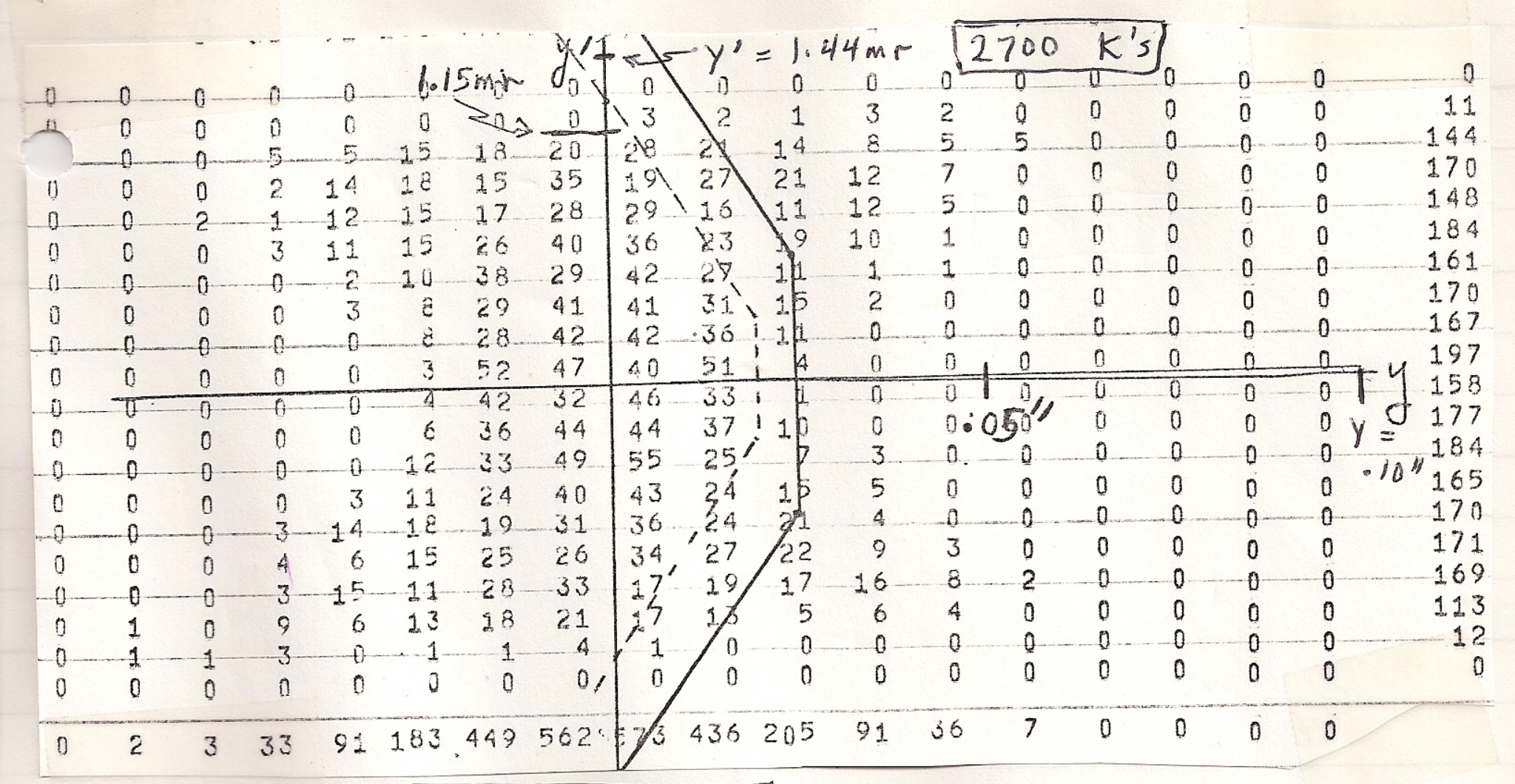

Mode MPS 4

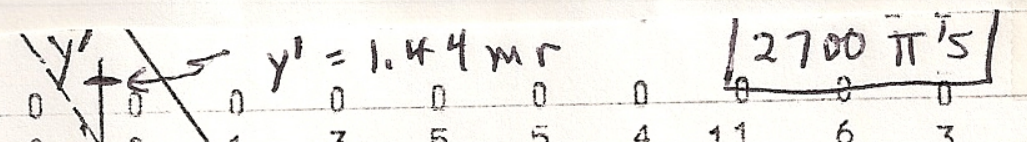

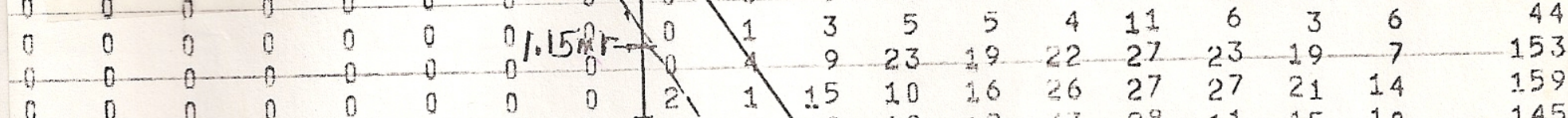

$\begin{array}{llllllll}0 & 0 & 0 & 0 & 0 & 0 & 0 & 0 \\ 0 & 0 & 0 & 0 & 0 & 0 & 0 & 0\end{array}$

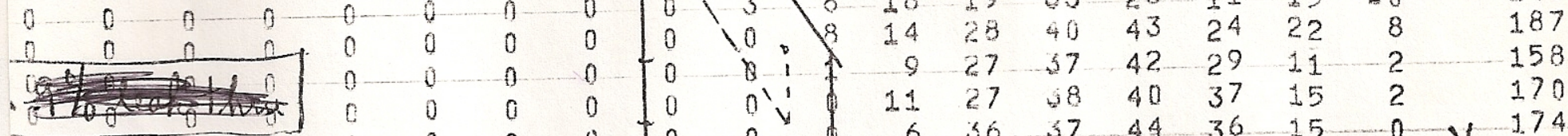

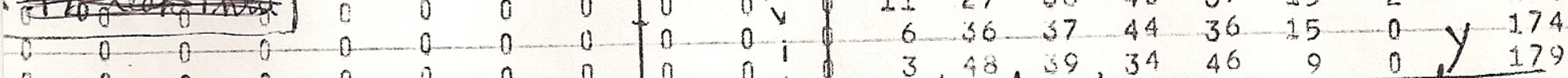

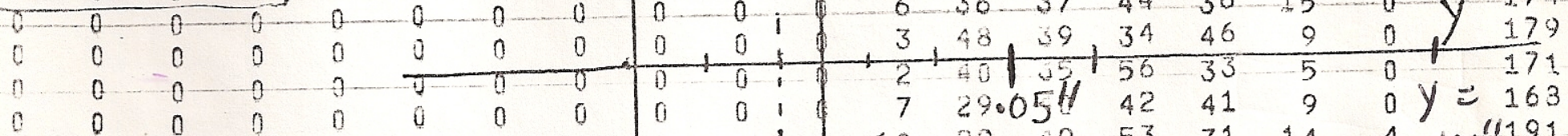

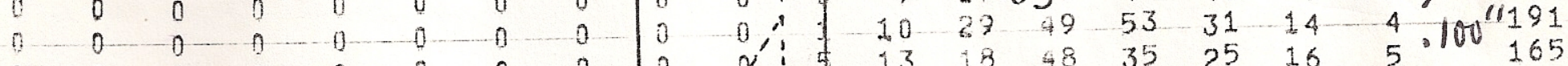

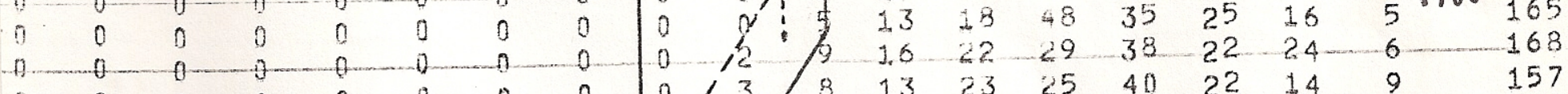
\begin{tabular}{lllllll|lll|lllllllll}
0 & 0 & 0 & 0 & 0 & 0 & 0 & 0 & 0 & 1 & 3 & 13 & 23 & 25 & 40 & 22 & 14 & 9 & 157 \\
0 & 1, & 2 & 17 & 27 & 27 & 21 & 26 & 18 & 16 & 165
\end{tabular}

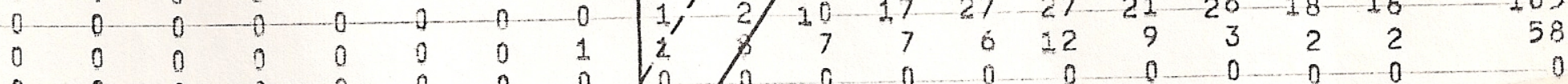

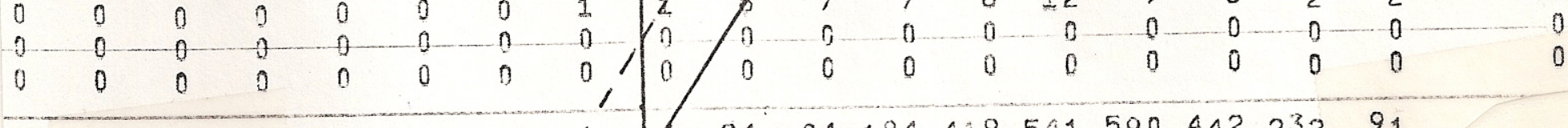
$0 \quad 0 \quad 0 \quad 0 \quad 0 \quad 0 \quad 001$ A 248418441954159044223291

\section{Fig. 5- Mode MPS 4 \\ (see Fig. I caption)}

(dotted line is a "tighten" slit) 


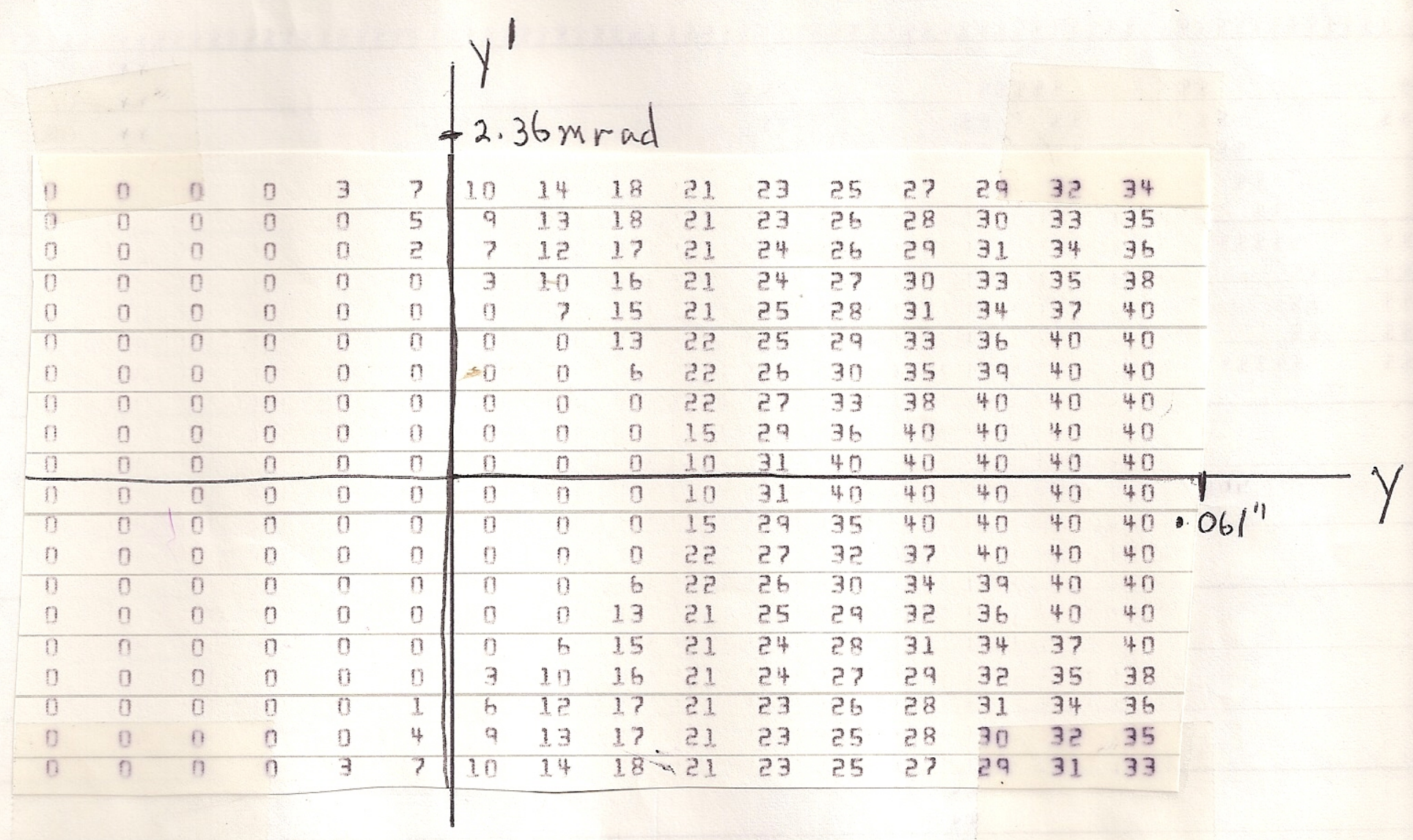

Fig. 6 - Scatterplot of the length of material traversed (inches) by a particle in the mass sit, as a function of $y$ and $y^{\prime}$ at the center of the mass sit, for mode $3 E$. 


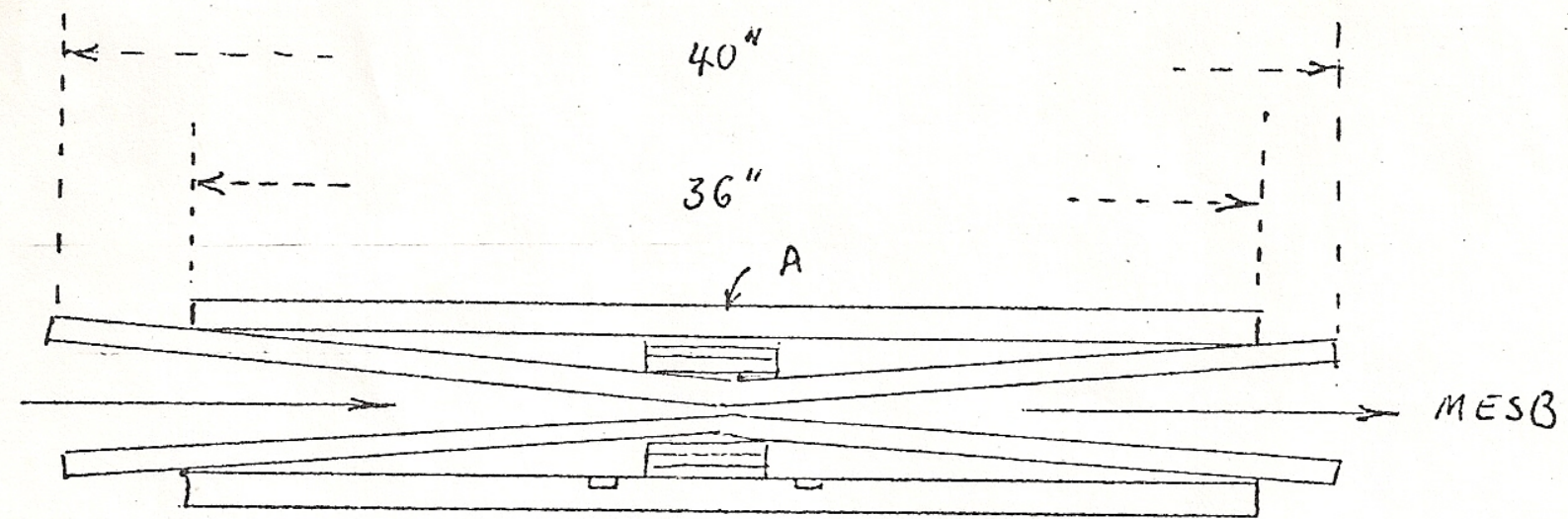

$$
\begin{aligned}
& \text { Mass slit } \\
& \text { (side view) } \\
& \text { (not drawn toscale) }
\end{aligned}
$$

$$
\text { Fig.7 }
$$

